\title{
Pertussis immunization for adolescents: What are we waiting for?
}

\author{
Scott A Halperin MD
}

$\mathrm{I}^{\mathrm{I}}$ mmunization against pertussis (whooping cough) has been 1 part of the routine childhood immunization program for over 50 years. Until 1997, a whole cell pertussis vaccine was used, most often combined with diphtheria and tetanus toxoids; in some jurisdictions it was combined with inactivated poliovirus vaccine and later with Haemophilus influenzae type $\mathrm{b}$ (Hib)-conjugate vaccine. Vaccine doses were given at two, four, six and 18 months of age, and again at four to six years of age. Use of the whole cell vaccine in children seven years of age and older was not recommended because "the incidence and severity of the disease greatly decrease with age, and because adverse reactions are (may be) more common in older children and adults..." (1-3). Over a one-year period in 1997/98, all provinces in Canada began using an acellular pertussis vaccine, again combined with diphtheria and tetanus toxoids, inactivated poliovirus vaccine and Hibconjugate vaccine. In 1999, an acellular pertussis vaccine that was combined with tetanus and diphtheria toxoids (TdaP) (Adacel, Aventis Pasteur, Canada) was licensed for use in individuals 12 to 54 years of age in Canada. In Germany, a similar adolescent and adult TdaP was licensed in 2000 (Boostrix, SmithKline Beecham, Belgium). With the availability of a TdaP product in Canada, should routine universal immunization against pertussis be provided for all adolescents and adults? Some of the key issues to be considered when answering this question are addressed in the questions and answers that follow. The focus of the present paper is on the adolescent population; however, similar issues about adult immunization need to be addressed by internal medicine and family practice practitioners.

\section{HOW FREQUENT IS PERTUSSIS IN ADOLESCENTS?}

Pertussis continues to be primarily a disease of childhood; most cases are reported in children younger than five years of age, with the highest incidence (and the highest morbidity and mortality rates) in infants younger than one year of age. Over the past 10 years, there has been a resurgence of pertussis from an average of 1000 to 2000 cases reported to the notifiable disease surveillance system annually to 7000 to 10,000 cases reported annually (4). The most rapid increase in cases of pertussis has occurred in adolescents. In $1986,5.2 \%$ of patients with pertussis in Canada were adolescents aged 10 to 19 years (1.4\% of patients were adults who were at least 20 years of age). In 1992, adolescents accounted for $11.2 \%$ of reported cases (adults $6.2 \%$ ) and by 1997 , adolescents accounted for $20 \%$ of reported cases (adults $11.7 \%)(4,5)$. In addition, large community outbreaks of pertussis in adolescents have been reported in New Brunswick, British Columbia and the United States $(6,7)$. These passive surveillance systems most likely under-report the incidence of pertussis in the population. Pertussis, as an adolescent and adult illness, is not unique in Canada. In the United States, pertussis in adolescents is also increasingly being recognized and reported (8). Both seroepidemiological studies (9-11), and studies of cough illness in adolescents and adults (12-17) suggest that pertussis is a frequent cause of prolonged cough. Difficulties in culture confirmation of pertussis in adolescents and adults (18) hinder precise determinations of the true proportion of cough illness due to Bordetella pertussis; reliance on serological diagnosis remains fraught with nonstandardized assays and varying serological definitions of positivity. Estimates of the role of pertussis in prolonged cough illness in adolescents and adults range from $1 \%$ to $25 \%(12-18)$.

\section{WHAT ARE THE CLINICAL CHARACTERISTICS OF PERTUSSIS IN ADOLESCENTS?}

Pertussis in adolescents can range from a nonspecific, prolonged cough illness to classical pertussis that includes a paroxysmal cough, post-tussive vomiting and whoop. The 
mean duration of the cough has been reported to be from 43 to 49 days; however, these data may be skewed by a reporting bias that results from the underdiagnosis of milder cases $(17,19)$. Until more complete identification of pertussis in adolescents and adults is possible, it will not be possible to describe the spectrum of disease presentation and frequency. Although the complications of the disease that are common in infants, such as apnea and pneumonia, are unusual in adolescents and adults, adolescents and adults may suffer rib fracture, conjunctival hemorrhage, rectal prolapse or urinary incontinence $(19,20)$.

\section{DOES PERTUSSIS IN ADOLESCENTS POSE ANY OTHER RISKS?}

Although the manner in which pertussis spreads in the community is not completely understood, it is clear that adolescents (and adults) appear to be infected by younger schoolaged and preschool-aged children, and adolescents (and adults) are the source of infection of young infants (21-24). In one outbreak, having an adolescent mother was an important risk factor for pertussis in infants younger than one year of age (25). This observation is particularly worrying because of the increased morbidity and mortality from pertussis in the younger age group.

\section{IS THE ACELLULAR PERTUSSIS VACCINE SAFE FOR ADOLESCENTS?}

Currently, one acellular pertussis vaccine (Adacel) is licensed for use in adolescents in Canada. In prelicensure studies in over 2000 adolescents and adults, the TdaP vaccine was well tolerated; the most frequent adverse reactions were redness (in $11 \%$ to $22 \%$ of patients) and tenderness at the injection site (in $88 \%$ of patients) $(26,27)$. Systemic reactions were much less common; fever was reported by $1 \%$ to $5 \%$ of vaccine recipients. There were no differences in the rates of reactions between recipients of the TdaP vaccine and those who were given the standard (adult type) tetanusdiptheria toxoid (Td) vaccine; this suggests that the addition of the acellular pertussis vaccine component did not significantly increase the adverse events associated with the immunization.

\section{IS THE ACELLULAR PERTUSSIS VACCINE EFFECTIVE FOR ADOLESCENTS?}

Acellular pertussis vaccines induce a vigorous antibody response in adolescents to all of the antigens contained in the vaccine (26-28). Although serological correlates of immunity are not well established, the antibody levels achieved after vaccination with Adacel are well in excess of those measured in studies that established the efficacy of the vaccine in infants who received the three-dose primary series (29). An efficacy study using Boostrix in adolescents and adults in the United States has been completed and will soon be reported, but it is not yet clear whether the study will have sufficient power to assess efficacy adequately.

\section{WHAT DOES THE NATIONAL ADVISORY COMMITTEE ON IMMUNIZATION RECOMMEND?}

The Canadian National Advisory Committee on Immunization (NACI) statement on TdaP (30) concludes that a single dose of TdaP in adolescents and adults "....increases their pertussis antibody levels far in excess of those observed in Sweden in infants who receive three doses of acellular pertussis vaccine..." and that "as the efficacy demonstrated in the Swedish trial was $85 \%$ ( $95 \%$ confidence interval: $81 \%$ to $89 \%$ ), it is reasonable to expect that the protection against severe disease in adolescents and adults would be of the same order, and this may lead to reduced transmission." However, NACI concludes and recommends that TdaP “...can be used to replace the adolescent booster dose of Td for those individuals who wish to have protection. There are no data available at the moment on which to base a recommendation for universal routine use".

\section{IS NACI CORRECT IN ITS RECOMMENDATION?}

The shortest answer to this questions is both yes and no. NACl's summary of the data is accurate; one can only infer from the available data that a single dose of TdaP is effective in preventing pertussis. Neither the duration of protection nor the need for subsequent doses is known; however, data from an early study with a single booster dose with another acellular pertussis vaccine indicate that antibody levels remain above prebooster levels for at least eight years (31). Data available for the adolescent dose are similar to that available for the 18-month reinforcing dose and the preschool booster; these doses were implemented to replace the doses given with the whole cell vaccine, without data on their efficacy or the duration of immunity after the primary series. It is clear that adolescents are susceptible to pertussis due to waning immunity following their preschool dose (32). Perhaps as a result of NACl's overly negative assessment of the strength of evidence for universal adolescent immunization, only one province (Newfoundland) has implemented a routine adolescent immunization program.

\section{WHAT SHOULD BE DONE?}

Many steps can be taken to control further pertussis in adolescents and adults (and perhaps in infants, as an additional benefit). Manufacturers should provide additional data that are necessary to convince advisory committees and program planners about the benefits of universal adolescent pertussis immunization. This information should include efficacy data (perhaps using pertussis outbreaks as a scenario for a vaccine clinical trial) or effectiveness data gathered via enhanced surveillance before and after the implementation of universal immunization programs in selected jurisdictions. Licensure of an adult formulation acellular pertussis vaccine alone (not combined with $\mathrm{Td}$ ) will facilitate the provision of vaccine to adolescents who were recently immunized with $\mathrm{Td}$. Practising physicians should be more aware of the possible occurrence of pertussis in older children and adults, and attempt to confirm the diagnosis. Enhanced reporting of sus- 
pected and confirmed cases of pertussis would better define the true burden of illness. Public health officials should also make surveillance of pertussis in adolescents and adults a higher priority to identify outbreaks at an earlier stage (which may facilitate a clinical efficacy trial), and to provide the necessary information on which program planners can make decisions about the implementation of universal immunization programs. Despite the NACI recommendations, program planners in each province should review the clinical, epidemiological and clinical trial data so that decisions can be made using the same criteria used to implement other vaccine and health interventions. In the interim, paediatricians and family physicians should make acellular pertussis vaccine available to their patients, particularly in areas where outbreaks of pertussis occur. As with all vaccines, adolescents and parents should be given the information that is available on the risks and benefits of this immunization as a part of the normal informed consent process.

\section{REFERENCES}

1. Canadian Immunization Guide, 2nd edn, 1984. Ottawa: Health Canada, 1984.

2. Canadian Immunization Guide, 3rd edn, 1989. Ottawa: Health Canada, 1989.

3. Canadian Immunization Guide, 4th edn, 1993. Ottawa: Health Canada, 1993.

4. Laboratory Centre for Disease Control. Notifiable Diseases Annual Summary 1996. Can Commun Dis Rep 1998;24(Suppl 6):21-3.

5. Laboratory Centre for Disease Control. Notifiable Diseases Annual Summary 1992. Can Commun Dis Rep 1994;20(Suppl 1):37.

6. Brennan M, Strebel P, George H, et al. Evidence for transmission of pertussis in schools, Massachusetts, 1996: Epidemiological data supported by pulsed-field gel electrophoresis studies. J Infect Dis 2000;181:210-5.

7. Mink CM, Sirota NM, Nugent S. Outbreak of pertussis in a fully immunized adolescent and adult population. Arch Pediatr Adolesc Med 1994;148:153-7.

8. Guris D, Strebel PM, Bardenheier B, et al. Changing epidemiology of pertussis in the United States: Increasing reported incidence among adolescents and adults, 1990-1996. Clin Infect Dis 1999;28:1230-7.

9. Schmitt-Grohe S, Cherry JD, Heininger U, Uberall MA, Pineda E, Stehr K. Pertussis in German adults. Clin Infect Dis 1995;21:860-6.

10. Deville JG, Cherry JD, Christenson PD, et al. Frequency of unrecognized Bordetella pertussis infection in adults. Clin Infect Dis 1995;21:639-42.

11. Cromer BA, Goydos J, Hackell J, Mezzatesta J, Dekker C, Mortimer EA. Unrecognized pertussis infection in adolescents. Am J Dis Child 1993;147:575-7.

12. Nennig ME, Shinefield HR, Edwards KM, Black SB, Fireman BH. Prevalence and incidence of adult pertussis in an urban population. JAMA 1996;275:1672-4.
13. Jansen DL, Gray GC, Putnam SD, Lynn F, Meade BD. Evaluation of pertussis in U.S. Marine Corps trainees. Clin Infect Dis 1997;25:1099-1107.

14. Mink CM, Cherry JD, Christenson P, et al. A search for Bordetella pertussis infection in university students. Clin Infect Dis 1992;14:464-71.

15. Wright SW, Edwards KM, Decker MD, Zeldin MH. Pertussis infection in adults with persistent cough. JAMA 1995;273:1044-6.

16. Aoyama T, Takeuchi Y, Goto A, Iwai H, Murase Y, Iwata T. Pertussis in adults. Am J Dis Child 1992;146:163-6.

17. Senzilet LD, Halperin SA, Spika JS, et al. Pertussis is a frequent cause of prolonged cough illness in adults and adolescents. (In press)

18. Marchant CD, Loughlin AM, Lett SM, et al. Pertussis in Massachusetts, 1981-1991: Incidence, serologic diagnosis, and vaccine effectiveness. J Infect Dis 1994;169:1297-1305.

19. Postels-Multani S, Schmitt HJ, Wirsing von Konig CH, Bock HL, Bogaerts H. Symptoms and complications of pertussis in adults. Infection 1995;23:139-42.

20. De Serres G, Shadmani R, Duval B, et al. Morbidity of pertussis in adolescents and adults. J Infect Dis 2000;182:174-9.

21. Long SS, Welkon CJ, Clark JL. Widespread silent transmission of pertussis in families: Antibody correlates of infection and symptomatology. J Infect Dis 1990;161:480-6.

22. Mertsola J, Ruuskanen O, Eerola E, Viljanen MK. Intrafamilial spread of pertussis. J Pediatr 1983;103:359-63.

23. Mortimer EA. Pertussis and its prevention: A family affair. J Infect Dis 1990;161:473-9.

24. Wirsing von Konig CH, Postels-Multani S, Bock HL, Schmitt HJ. Pertussis in adults: Frequency of transmission after household exposure. Lancet 1995;346:1326-9.

25. Izurieta HS, Kenyon TA, Strebel PM, Baughman AL, Shulman ST, Wharton M. Risk factors for pertussis in young infants during an outbreak in Chicago in 1993. Clin Infect Dis 1996;22:503-7.

26. Halperin SA, Smith B, Russell M, et al. Adult formulation of a five-component acellular pertussis vaccine combined with diphtheria and tetanus toxoids and inactivated poliovirus vaccine is safe and immunogenic in adolescents and adults. Pediatr Infect Dis I 2000;19:276-83.

27. Halperin SA, Smith B, Russell M, et al. An adult formulation of a five-component acellular pertussis vaccine combined with diphtheria and tetanus toxoids is safe and immunogenic in adolescents and adults. Vaccine 2000;18:1312-9.

28. Van der Wielen M, Van Damme P, Joossens E, Francois G, Meurice F, Ramalho A. A randomised controlled trial with a diphtheria-tetanus-acellular pertussis (dTpa) vaccine in adults. Vaccine $2000 ; 18: 2075-82$.

29. Gustafsson L, Hallander HO, Olin P, Reizenstein E, Storsaeter J. A controlled trial of a two-component acellular, a fivecomponent acellular, and a whole-cell pertussis vaccine. N Engl J Med 1996;334:349-55.

30. National Advisory Committee on Immunization. Statement on adult/adolescent formulation of combined acellular pertussis, tetanus, and diphtheria vaccine. Can Commun Dis Rep 2000;26(ACS-1):1-8.

31. Tran Minh NN, He Q, Edelman K, et al. Immune responses to pertussis antigens eight years after booster immunization with acelullar vaccines in adults. Vaccine 2000;18:1971-4.

32. Lambert HP. Epidemiology of a small pertussis outbreak. Public Health Rep 1965;80:365-9.

\section{INFECTIOUS DISEASES AND IMMUNIZATION COMMITTEE}

Members: Drs Upton Allen, The Hospital for Sick Children, Toronto, Ontario; H Dele Davies, Division of Infectious Diseases, Alberta Children's Hospital, Calgary, Alberta; Joanne Embree, The University of Manitoba, Winnipeg, Manitoba (chair); Mireille Lemay, Department of Infectious Diseases, Sainte-Justine Hospital, Montréal, Québec; Gary Pekeles, The Montreal Children's Hospital, Montreal, Quebec (director responsible) Consultants: Drs Noni MacDonald, Faculty of Medicine, Dalhousie University, Halifax, Nova Scotia; Victor Marchessault, Cumberland, Ontario Liaisons: Drs Susan King, Division of Infectious Diseases, The Hospital for Sick Children, Toronto, Ontario (Canadian Paediatric AIDS Research Group); Monique Landry, Direction de la santé publique de Laval, Laval, Québec (Public Health); Larry Pickering, Centre for Pediatric Research, Norfolk, Virginia (American Academy of Pediatrics); John Waters, Alberta Health, Edmonton, Alberta (Epidemiology) Principal author: Dr Scott Halperin, Department of Pediatrics, IWK-Grace Health Centre, Halifax, Nova Scotia (IMPACT) 


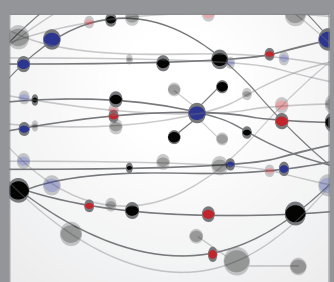

The Scientific World Journal
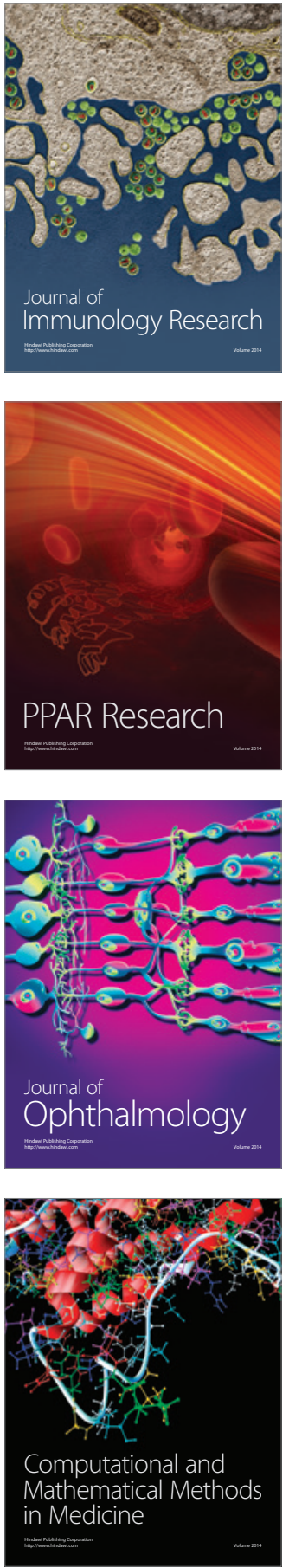

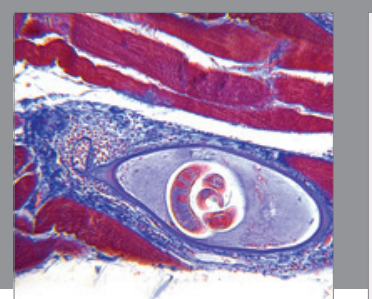

Gastroenterology Research and Practice

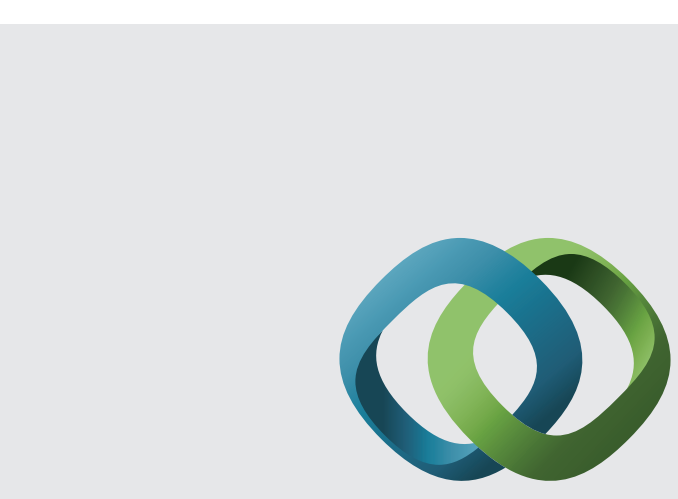

\section{Hindawi}

Submit your manuscripts at

http://www.hindawi.com
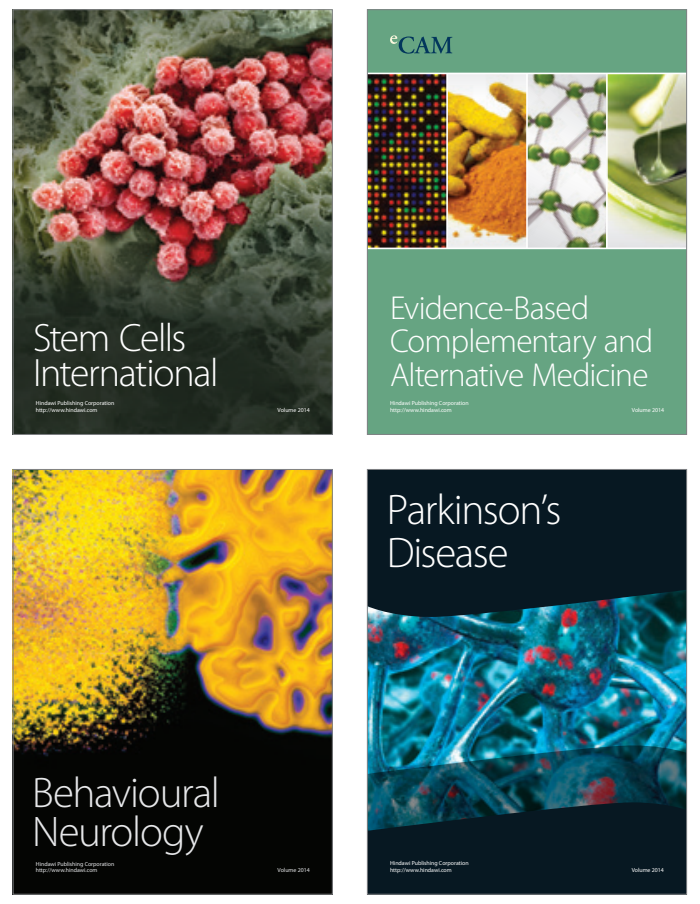
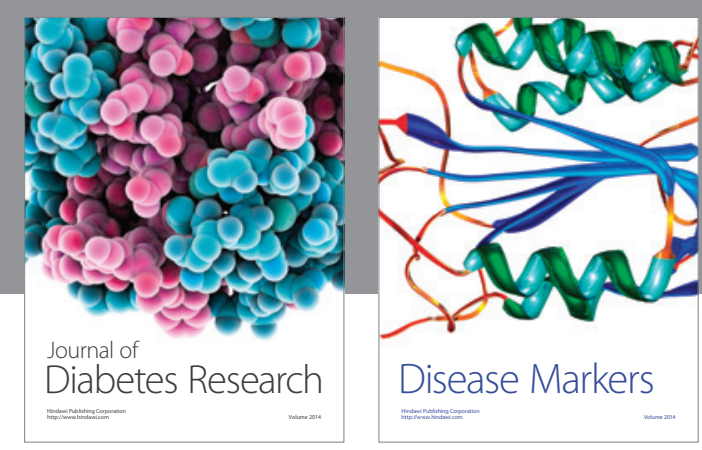

Disease Markers
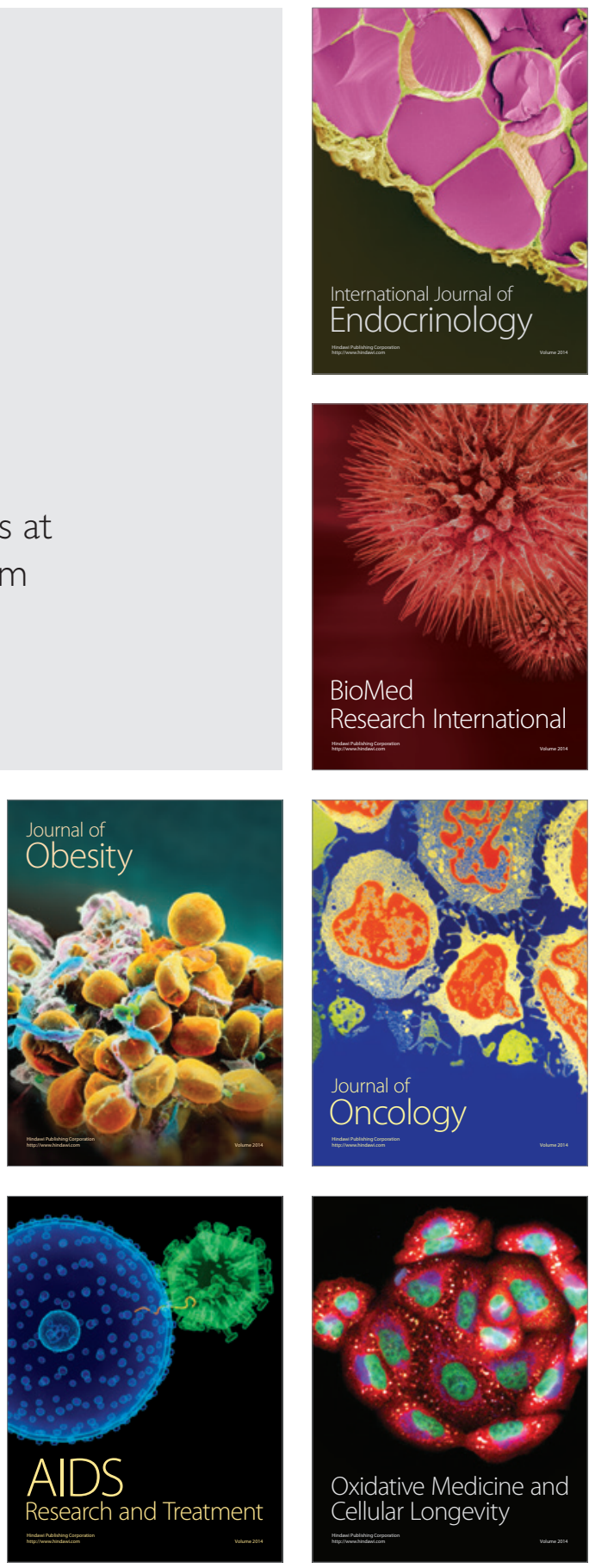